\title{
Ageing, recognition and partial learning
}

\author{
JAMES HARTLEY AND IAIN S. MARSHALL
} UNIVERSITY OF KEELE, ENGLAND

Old $S$ s were required to recognize previously presented verbal materials embedded in (1) different and (2) similar materials. It was hypothesized that if recognition scores were "inflated" by partial learning, then scores in Condition I should be greater than scores in Condition 2. No differences were observed.

Recent work on memory and ageing has concentrated on the locus of memory loss. Schonfield \& Robertson (1965) demonstrated that while the free recall of Ss for verbal material declined steadily with age, recognition scores for similar material remained constant. Their results, they suggested, demonstrated that it was retrieval from storage that presented older people with particular difficulty, rather than any deficiency in the storage system itself.

McNulty \& Caird (1966) criticized these conclusions on the grounds that although the recognition scores did not decline with age, this did not necessarily imply that there were no differences in the amounts stored by the various age groups. They argue (following McNulty, 1965) that only part of an input needs to be stored in order to recognize later the complete input. Thus, as Ss get older, the total amount stored may decrease (as the Schonfield and Robertson recall scores show), but this may not be revealed in recognition scores. Put another way, recognition scores are "inflated"' by partial learning.

McNulty and Caird suggest that one way to test this hypothesis would be to use a series of recognition tests which require more and more complete learning of the items: They argue that recognition tests in which correct and incorrect alternatives are made more and more similar to each other should be increasingly affected by age. The experiment reported below was designed to test this hypothesis more simply by looking at extremes: Elderly Ss were required to carry out two recognition tasks, one requiring much more complete learning than the other.

Materials

Two presentation lists "A" and "B" were drawn up, each containing 12 monosyllabic or bisyllabic words chosen on the basis of frequency from the Thorndike-Lorge count. Each list contained words of very high frequency as reported in the section devoted to the first 1000 words. Each word was printed 2 in. high on a white card.

Two recognition lists were duplicated, each containing key words from a presentation list randomly positioned among four "distractors"' (incorrect alternatives). In one list (List A), the distractors were words of different letter combinations from the key word (e.g., old, black, tin, money, carry) whereas in the. other list (List B) they were more similar in letter combination, and sometimes in sound (e.g., hair, hale, hail, hare, hear).

\section{Procedure}

Thirteen Ss, nine males and four females, mean age 78 years (range 70-85), were tested in three groups $(\mathrm{N}=4,4$, and 5 ). Ss sat around $\mathrm{E}$ at a distance of about $6 \mathrm{ft}$ from the point of presentation. $E$ instructed as follows: "I have a pile of 12 cards here, each with a word printed on it. As soon as I show you a card I want you to say the word out loud once. Try to remember as many words as you can. Don't worry if you forget some of the words, nobody has ever remembered them all." Each word was presented in turn for $4 \mathrm{sec}$. Immediately after the Ss had pronounced the last word in the list they were instructed to turn over a sheet of paper previously given to them, and to underline the one word in each group of five that they had just seen presented. The recognition tests were untimed. All Ss did List A first, followed by List B.

The results of the experiment are shown in Table 1. Results and Discussion

It is clear that there is no significant difference between the mean scores obtained from List $A$ and List $B$. These results, therefore, provide no evidence for the recognition scores of List $A$ being inflated by partial learning. This suggests that either the McNulty and Caird hypothesis must be rejected, or that a different approach to teasing out partial learning is required. It may be that List $A$ did not present for the Ss a sufficiently different task from List B. If (as McNulty (1965) suggested) words are learned in "units" rather than parts, then no differences in recognition scores would emerge. This, however, points to a fun-

\begin{tabular}{|c|c|c|}
\hline Subject No. & List A & List B \\
\hline 1 & 8 & 10 \\
\hline 2 & 6 & 7 \\
\hline 3 & 6 & 5 \\
\hline 4 & 5 & 7 \\
\hline 5 & 9 & 8 \\
\hline 6 & 1 & 1 \\
\hline 7 & 9 & 8 \\
\hline 8 & 10 & 6 \\
\hline 9 & 1 & 2 \\
\hline 10 & 6 & 10 \\
\hline 11 & 4 & 6 \\
\hline 12 & 6 & 5 \\
\hline 13 & 11 & 7 \\
\hline Mean & 6.3 & 6.3 \\
\hline Standard Deviation & 2.9 & 2.5 \\
\hline
\end{tabular}


damental question here: Just what are the parts that are being stored for later recognition? Perhaps material similar to that used by McNulty in 1965 (i.e., statistical approximations to English) and groups of old and young Ss will be needed to demonstrate partial learning. Certain other factors of the McNulty (1965) experiment may be important too: There were four presentation trials, recognition tests were timed, and only one distractor was provided.

It was interesting to observe in our experiment that Ss were reluctant to underline words which they thought might be incorrect. Many Ss, despite the request to underline one word in each group, only underlined those they felt confident of getting right. A latency measure, had it been used, might have revealed differences between List $A$ and List $B$. An error analysis revealed no consistent patterns for either list.

Schonfield and Robertson presented lists containing 24 words-not all drawn from the high frequency population-and obtained a mean recognition score of 20 from their Ss. These data are clearly different from the data presented in Table 1 , but two factors may account for this. In the present experiment older and less intelligent Ss were used. Schonfield and Robertson report that their $\mathrm{Ss}(\mathrm{N}=22$, age range $60+)$ were "intellectually superior," whereas a more apt description of the Ss in the present experiment would be "average." As Schonfield and Robertson say, following Gilbert (1941), it might be expected that recognition scores of those of lower intelligence levels might show some loss. It is not possible for us, however, to state whether the differences between the results reflect a deficit in intelligence, a decline in storage, or both: It is interesting to note here, nevertheless, that several Ss in the present study complained about the difficulty of the task.

\section{Conclusions}

The results of this experiment did not support the hypothesis suggested by McNulty and Caird, but it has been argued that a more stringent control of materials may be required. If this should be the case, then this points to the difficulty of locating the parts in partial learning. The writers are thus skeptical concerning the use of recognition measures as a basis for discussing the locus of memory impairment.

\section{References}

GILBERT, J. C. Memory losses in senescence. J. Abnorm. Soc. Psychol, 1941, 36, 73-86.

McNULTY, J. A. An analysis of recall and recognition processes in verbal learning. J. verbal Learn. verbal Behav., 1965, 4, 430-436.

McNULTY, J. A., \& CAIRD, W. Memory loss with age: retrieval or storage? Psychol Rep., 1966, 19, 229-230.

SCHONFIELD, D., \& ROBERTSON, B. Memory storage and ageing. Canad. J. Psychol, 1966, 20, 228-236. 